European Journal of Pharmacology, 68 (1980) 89-92

(c) Elsevier/North-Holland Biomedical Press

Short communication

\title{
DIFFERENTIAL EFFECTS OF VARIOUS STIMULI ON AVP LEVELS IN BLOOD AND CEREBROSPINAL FLUID
}

\author{
WIM B.J. MENS, HENK J. BOUMAN, ELS A.D. BAKKER and TJEERD B. VAN WIMERSMA GREIDANUS \\ Rudolf Magnus Institute for Pharmacology, University of Utrecht, Vondellaan 6, 3521 GD Utrecht, The Nether- \\ lands
}

Received 4 August 1980, accepted 22 September 1980

W.B.J. MENS, H.J. BOUMAN, E.A.D. BAKKER and T.B. VAN WIMERSMA GREIDANUS, Differential effects of various stimuli on AVP levels in blood and cerebrospinal fluid, European J. Pharmacol. 68 (1980) 89-92.

Water deprivation, drinking water containing $2 \% \mathrm{NaCl}$, or systemic injection with histamine or nicotine markedly increased plasma levels of vasopressin in rats. In contrast, none of the applied stimuli changed vasopressin levels in the CSF collected simultaneously from the same animal. These data suggest that the blood levels of vasopressin are controlled quite differently from CSF levels of this hormone.

Vasopressin Cerebrospinal fluid Water deprivation Histamine Nicotine

\section{Introduction}

Water deprivation, hemorrhage, administration of hypertonic solutions of $\mathrm{NaCl}$ or injection of substances such as mannitol, histamine, dopamine, acetylcholine or angiotensin II enhance the release of vasopressin from the hypothalamo-neurohypophyseal system, which results in elevated plasma levels of this hormone (De Wied and Laszlo, 1967; Dogterom et al., 1978; Dunn et al., 1973; Sladek and Joynt, 1979; Tuomisto et al., 1980).

Heller et al. (1968) and Vorherr et al. (1968) showed the presence of antidiuretic activity in the cerebrospinal fluid (CSF) of rabbits and dogs under pentobarbitone anaesthesia and after hemorrhage respectively. The presence of vasopressin in the CSF of dogs and rats under anaesthesia was demonstrated by Dogterom et al. (1978). Vasopressin has also been measured in human CSF (Dogterom et al., 1978; Jenkins et al., 1980).

Vasopressin-containing neurons projecting to the floor of the third ventricle have been described by Rodriguez (1970). The endings of these neurons contain large granules typical of those containing vasopressin in the posterior pituitary gland and this appears to be at least one site of axonal secretion into the ventricular system.

In the present study the effects of water deprivation, of administration of $2 \% \mathrm{NaCl}$ and of treatment with nicotine and histamine on plasma vasopressin levels were compared with the effects on vasopressin levels in the CSF, in order to investigate whether or not there was a differential or concomitant release of this hormone into these body fluids.

\section{Materials and methods}

Male rats of an inbred Wistar strain (CPBTNO, Zeist, The Netherlands) weighing $180-220 \mathrm{~g}$ at the time of implantation of the cannulae were used. They were maintained on ad lib. food and water and housed in separate cages throughout the experiment. The lights were on between 5 am and $7 \mathrm{pm}$.

A permanent stainless steel cannula was implanted in the cisterna magna of rats. The cannula used in the present study was slightly dif- 
ferent from the one described by Bouman and van Wimersma Greidanus (1979) in that the cannula was not equipped with a separate outflow opening.

The right external jugular vein was cannulated with silicon medical grade tubing. In order to prevent coagulation of blood in the cannula, a solution of polyvinyl pyrrolydine (PVP)-heparin was injected into the cannula. Every second day fluid in the cannula was replaced by a fresh PVP-heparin solution.

Three experiments were performed. First, vasopressin levels were measured before, 24 , 48 and $72 \mathrm{~h}$ after water deprivation and in addition after $2 \mathrm{~h}$ access to normal drinking water of the $72 \mathrm{~h}$ water-deprived rats. Samples of blood $(0.5-0.7 \mathrm{ml})$ and CSF $(50-100$ $\mu$ ) were taken simultaneously from the same animal at the time-interval indicated. Second, drinking water was replaced by a solution of $2 \% \mathrm{NaCl}$ for $72 \mathrm{~h}$. The experiment was scheduled in the same way as outlined for the first experiment. Third, rats were injected i.p. with either $5.0 \mathrm{mg} / \mathrm{kg}$ histamine, $3.0 \mathrm{mg} / \mathrm{kg}$. nicotine or saline. Blood and CSF were taken simultaneously from different groups of animals at 5, 15 and 30 min after injection.

Arginine-vasopressin (AVP) was measured by radioimmunoassay (RIA) after extraction from plasma CSF with activated Vycor glass powder. The details of the extraction procedure and the RIA are described elsewhere (Dogterom et al., 1978). The antiserum used in a final dilution of $1: 10000$ was highly specific for AVP; the cross-reactivity with oxytocin being less than $0.1 \%$ and with vasotocin approximately $0.25 \%$. The standard curve was sensitive to $0.25 \mathrm{pg} \mathrm{AVP} /$ tube and the detection limit of the assay was $0.5 \mathrm{pg}$ AVP $/ \mathrm{ml}$. As standard and for preparation of the tracer a pure synthetic AVP preparation (Organon, Oss, The Netherlands, pressor activity $5091 \mathrm{U} / \mathrm{mg}$ ) was used. The results were corrected for recovery which was approximately $60 \%$.

Blood was collected in cooled, heparinized, polypropylene tubes and centrifuged subsequently at $4^{\circ} \mathrm{C}$ for $10 \mathrm{~min}$ at $3000 \mathrm{rpm}$. CSF samples from 2-3 animals were pooled. The samples were stored at $-20^{\circ} \mathrm{C}$ until testing.

The radioimmunoassay results were calculated on a Hewlett Packard 104 calculator programmed with a logit-curve fitting program. Statistical analysis was performed using Student's-t-test.

\section{Results}

Water deprivation resulted in a gradual increase of plasma AVP levels in rats. After $24 \mathrm{~h}$ of deprivation there was a 4-5 fold increase of plasma AVP and a 10 fold increase after $72 \mathrm{~h}$ (fig. 1B). These levels returned to basal values after $2 \mathrm{~h}$ access to normal drinking water. Replacing the drinking water by a $2 \%$ $\mathrm{NaCl}$ solution caused a similar rise of AVP plasma levels, although the maximal increase

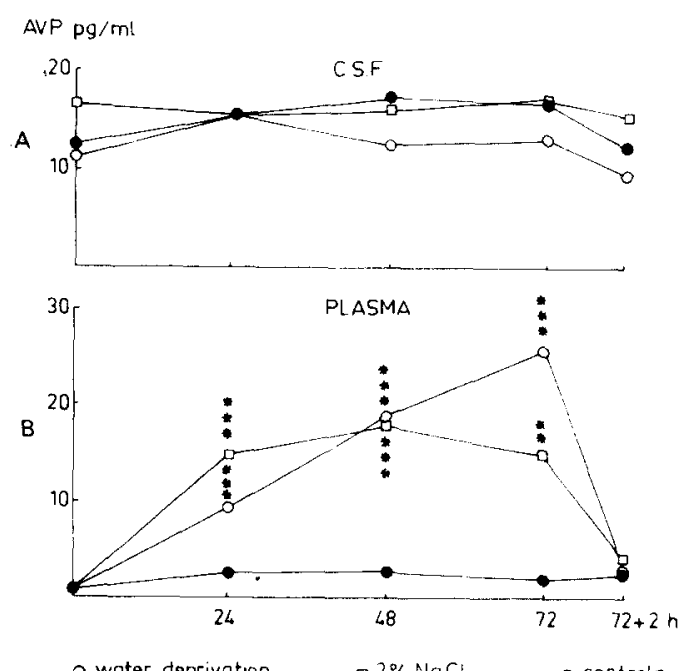

Fig. 1. AVP levels (pg/ml) in CSF and plasma after water deprivation (O) or replacement of drinking water by a $2 \% \mathrm{NaCl}$ solution (). Control animals (๑) had free access to normal drinking water. Samples of CSF and plasma were taken from the same animals before and at various times (h) after starting the experiment. All animals had access to normal drinking water between 72 and $74 \mathrm{~h}$. Each point represents the mean of 8-18 samples. S.E.M. was approximately $15 \%$ of the mean value. * Different from control animals (** $\mathrm{P}<0.01, * * * \mathrm{P}<0.001)$. 


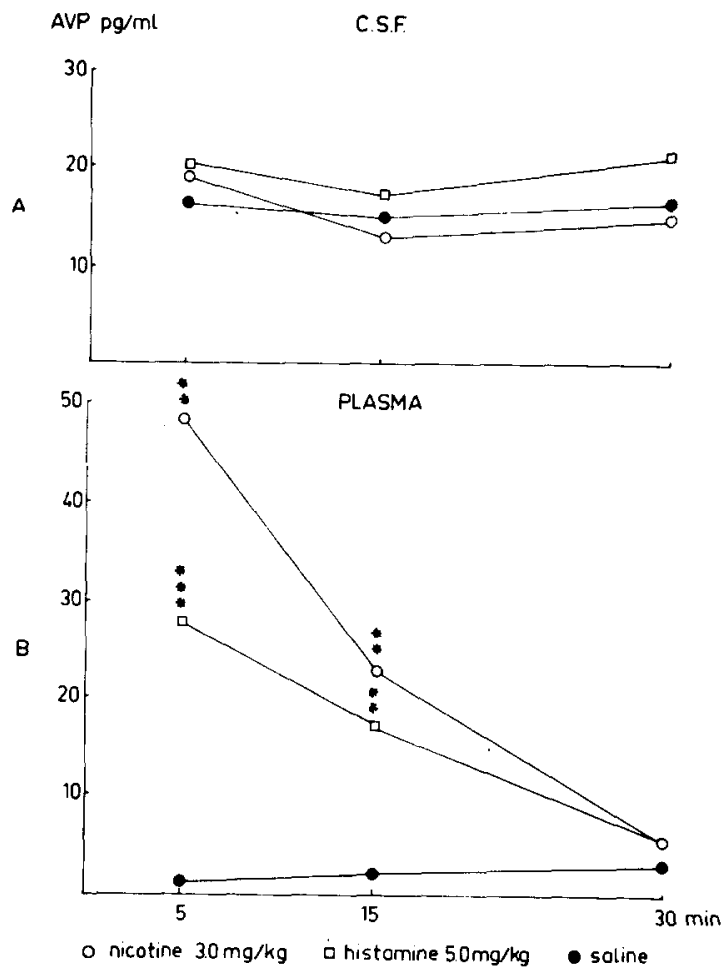

Fig. 2. Time course of AVP levels $(\mathrm{pg} / \mathrm{ml})$ and plasma following i.p. administration of either histamine (5.0 $\mathrm{mg} / \mathrm{kg}, \square)$, nicotine $(3.0 \mathrm{mg} / \mathrm{kg}, O)$ or saline $(0.5 \mathrm{ml}$, -). CSF and plasma samples were taken simultaneously from the same animal at different times after injection. Each point represents the mean of 6-10 samples. S.E.M. was approximately $20 \%$ of the mean value. * Different from saline-treated animals ${ }^{* *} \mathrm{P}<$ $0.01, * * * P<0.001)$.

was reached after $24 \mathrm{~h}$ (fig. 1B). Replacement of the $\mathrm{NaCl}$ solution by normal drinking water caused a decrease of AVP levels to basal values after $2 \mathrm{~h}$. In contrast to plasma AVP levels, CSF levels of AVP were changed by neither water deprivation nor presentation of a $2 \% \mathrm{NaCl}$ solution as drinking water (fig. 1A). After two withdrawals of CSF within $2 \mathrm{~h}$ the AVP content in the second sample tended to be lower than in the first one, but the decrease never reached statistical significance.

Both histamine and nicotine markedly elevated AVP plasma levels within $5 \mathrm{~min}$ after injection (fig. 2B). Increased plasma levels were also found $15 \mathrm{~min}$ after injection. At 30 min, the levels had returned to those in control rats. However, neither histamine nor nicotine altered the AVP content in CSF (fig. 2A).

\section{Discussion}

The present data show the presence of vasopressin in the CSF obtained from freely moving rats. The basal levels of this hormone were substantially higher in CSF than in plasma, which agrees well with data of Dogterom et al. (1978). Water deprivation, $2 \% \mathrm{NaCl}$, histamine and nicotine enhanced the release of vasopressin from the hypothalamo-neurohypophyseal system, resulting in elevated plasma levels of vasopressin. Dunn et al. (1973) and Dogterom et al. (1978) found that fluid restriction resulted in a progressive rise in plasma vasopressin to about 10 times basal levels after $96 \mathrm{~h}$. A 2-3 fold increase in plasma vasopressin occurred as early as $12 \mathrm{~h}$ (Dunn et al., 1973). An increased release of vasopressin after application of histamine or nicotine was reported by Sladek and Joynt (1979) and Tuomisto and Eriksson (1980).

In the present study, the vasopressin content of the CSF was not influenced by any of the stimuli applied whereas plasma vasopressin levels were affected. The vasopressin content of the cisternal CSF appears to be more stable and less affected by these stimuli than that of blood. Heller et al. (1968) showed that the antidiuretic activity of blood was at least twice as high as that of CSF in rabbits under pentobarbitone anaesthesia. In man, the mean concentration of vasopressin in CSF obtained by lumbar puncture is slightly lower than that in plasma. The differences between the ratios CSF-vasopressin and plasma-vasopressin in the various experiments might be due to the difference in species, to the anaesthesia used, or to the origin of the CSF (lumbar versus cisternal).

There is evidence that relatively few neurosecretory fibers reach the third ventricle in comparison with those ending on the neural lobe (Rodriguez, 1970). In the present experi- 
ments the neurons projecting to the third ventricle might have been stimulated but this may not have resulted in a significant change of vasopressin content in the CSF, due to the restricted number of vasopressin fibers involved.

A substantial increase in plasma vasopressin did not elevate the vasopressin content of the CSF, suggesting that the blood-CSF barrier is relatively impermeable for vasopressin. De Rotte et al. (1980) demonstrated that systemic administration of $\alpha$-melanocyte-stimulating hormone ( $\alpha-\mathrm{MSH})$ resulted in a significant rise of $\alpha \cdot \mathrm{MSH}$ levels in CSF. The rise of $\alpha-\mathrm{MSH}$ content of the CSF did not exceed $0.01 \%$ of the systemic dose initially injected.

The present data suggest that the mechanisms controlling CSF vasopressin levels are quite different from those affecting plasma levels of this hormone. They might also suggest that separate vasopressin-containing neuronal pathways exist, projecting either to the posterior pituitary or to the ventricular system of the brain.

\section{Acknowledgements}

The investigations were supported by the Foundation for Medical Research FUNGO which is subsidized by the Netherlands Organisation for the Advancement of Pure Research (ZWO). The stimulating and helpful comments by Dr. J.M. Van Ree during the preparation of this manuscript are gratefully acknowledged.

\section{References}

Bouman, H.J. and Tj.B. Van Wimersma Greidanus, 1979, A rapid and simple cannulation technique for repeated sampling of cerebrospinal fluid in freely moving rats, Brain Res. Bull. 4, 575 .

De Rotte, A.A., H.J. Bouman and Tj.B. Van Wimersma Greidanus, 1980, Relationships between $\alpha$-MSH levels in blood and in cerebrospinal fluid, Brain Res. Bull. (in press).

De Wied, D. and F.A. Laszlo, 1967, Effect of autonomic blocking agents on ADH-release induced by hyperosmoticity, J. Endocrinol. 37, XVI.

Dogterom, J., Tj.B. Van Wimersma Greidanus and D. De Wied, 1978, Am. J. Physiol. 234, E 463.

Dunn, F.L., 'T.J. Brennen, A.E. Nelson and G.L. Robertson, The role of blood osmolality and volume in regulating vasopressin secretion in the rat, J. Clin. Invest. 52, 3212.

Heller, H., S. Hasan and A.G. Saifi, 1968, Antidiuretic activity in the cerebrospinal fluid, J. Endocrinol. 41, 273.

Jenkins, J.S., H.M. Mather and V. Ang, 1980, Vasopressin in human cerebrospinal fluid, J. Clin. Endocrinol. Metab. 50, 364.

Rodriguez, E.M., 1970, Morphological and functional relationships between the hypothalamo-neurohypophyseal system and cerebrospinal fluid, Aspects of Neuroendocrinol.; V Intern. Symp. on Neurosecr., Kiel, eds. W. Bargmann and B. Scharrer, (Springer, Berlin).

Sladek, C.D. and R.J. Joynt, 1979, Cholinergic involvement in osmotic control of vasopressin release by the organ-cultured rat hypothalamoneurohypophyseal system, Endocrinology 105 , 367.

Tuomisto, L., L. Eriksson and F. Fyhrquist, 1980, Vasopressin release by histamine in the conscious goat, European J. Pharmacol. 63, 15.

Vorherr, H., M.W.B. Bradbury, M. Hoghough and C.R. Kleeman, 1968, Antidiuretic hormone in cerebrospinal fluid during endogenous and exogenous changes in blood level, Endocrinology 83, 246. 